\title{
Comparative study between pull (reverse breech technique) and push (conventional technique) during cesarean delivery in obstructed labor
}

\author{
Sarkar D. ${ }^{1}$, Mandal S. ${ }^{2 *}$, Murmu M. ${ }^{3}$, Sarumathy K.A. ${ }^{4}$, Raj R. ${ }^{5}$, Khatoon S. \\ DOI: https://doi.org/10.17511/joog.2020.i01.03
}

1 Dipnarayan Sarkar, Assistant Professor, Department of Obstetrics and Gynaecology, Institute of Post Graduate Medical Education and Research, Kolkata, West Bengal, India.

2* Sarbeswar Mandal, Associate Professor, Department of Obstetrics and Gynaecology, Institute of Post Graduate Medical Education and Research, Kolkata, West Bengal, India.

3 Masihon Murmu, RMO-CT(G and O), Department of Obstetrics and Gynaecology, Institute of Post Graduate Medical Education and Research, Kolkata, West Bengal, India.

${ }^{4}$ Sarumathy K.A., Senior Resident, Department of Obstetrics and Gynaecology, Institute of Post Graduate Medical Education and Research, Kolkata, West Bengal, India.

5 Rituparna Raj, Senior Resident, Department of Obstetrics and Gynaecology, Institute of Post Graduate Medical Education and Research, Kolkata, West Bengal, India.

6 Shabina Khatoon, Senior Resident, Department of Obstetrics and Gynaecology, Institute of Post Graduate Medical Education and Research, Kolkata, West Bengal, India.

Aims and Objectives: To compare the maternal and neonatal morbidities and to identify the etiology of obstructed labor and retrospective analyze the pull and push techniques for delivery of impacted head during cesarean section. Method: This observational study was conducted in IPGME and R, SSKM medical college from April 2015 to Feb 2019. The study population included 74 women tackled with the pull method, while the control group comprised 74, age and parity matched who underwent the push method of head delivery. Results: A review of 74 patients revealed the average age of the study population was $25.7 \pm 2$ years. Patients with anemia ( $\mathrm{Hb} \leq 8.5$ to $10 \mathrm{gm} / \mathrm{dl})$ and abnormal BMI (>30and $<24$ ) were observed to suffer more from obstructed labor $(p \leq 0.050)$. On the other hand, maternal height was not found to predict obstructed labor $(p=0.5300)$. Conclusion: Although the pull method may lead to some neonatal complications, it is associated with lower maternal morbidity than push method in impacted fetal head extraction during cesarean delivery.

Keywords: Disimpacted, reverse breech, push method, obstructed labor, fetomaternal outcome, occiput-posterior

\section{Corresponding Author}

Sarbeswar Mandal, Associate Professor, Department of Obstetrics and Gynaecology, Institute of Post Graduate Medical Education and Research, Kolkata, West Bengal, India.

Email: dr.sss.mandal@gmail.com
How to Cite this Article

Sarkar D, Mandal S, Murmu M, Sarumathy KA, Raj R, Khatoon S. Comparative study between pull (reverse breech technique) and push (conventional technique) during cesarean delivery in obstructed labor. Obs Gyne Review J Obstet Gynecol. 2020;6(1):14-24. Available From https://obstetrics.medresearch.in/ index.php/joog/article/view/101
To Browse

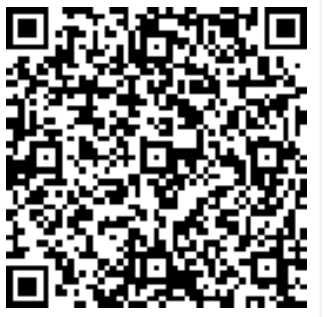

Manuscript Received 20-01-2020

Conflict of Interest No

Review Round 1
$30-01-2020$
Funding
Nil

(c) 2020 by Dipnarayan Sarkar, Sarbeswar Mandal, Masihon Murmu, Sarumathy K.A., Rituparna Raj, Shabina Khatoon and Published by Siddharth Health Research and Social Welfare Society. This is an Open Access article licensed under a Creative Commons Attribution 4.0 International License https://creativecommons.org/licenses/by/4.0/ unported [CC BY 4.0].

\begin{tabular}{|c|c|}
\hline $\begin{array}{c}\text { Review Round } 2 \\
06-02-2020\end{array}$ & Review Round 3 \\
\hline $\begin{array}{c}\text { Ethical Approval } \\
\text { Yes }\end{array}$ & $\begin{array}{c}\text { Plagiarism X-checker } \\
14 \%\end{array}$ \\
\hline
\end{tabular}

Accepted $11-02-2020$

Note 


\section{Introduction}

There is no clear definition and confusion of terms used by different authors remains [1]. The term "dystocia" is most frequently used as an equivalent for obstructed labor, but it covers a broad range of conditions, from labor lasting more than 12 hours to uterine rupture, fetal-pelvic disproportion or abnormal fetal presentation. Moreover, estimating the duration of labor may be difficult, especially in settings without appropriate monitoring technology. It is, however, accepted that if the obstruction cannot be overcome by manipulation or instrumental delivery, cesarean section is needed.

Prolong obstructed labor is one of the most common obstetrics complications in a developing country. Prolong obstruction in the second stage leads to a gradual impaction of the head in the pelvis and it is stressful for mother and fetus. It is the arrest of vaginal delivery of the fetus due to mechanical obstruction (despite adequate uterine contractions), it is defined as "obstructed labor" [2]. It has been documented in global Burden of Obstructed labor (GBD in the year 2000) by WHO that the incidence of obstructed labor is $4 \%$ to $6 \%$ and it accounts for $9 \%$ of all maternal death globally [3]. Obstructed labor incidence per 100 live births ranged from $3.06 \%$ to $17.3 \%$ in developing countries whereas in developed countries it is 1.8 to $4 \%$ [2]. At the same time associated fetomaternal morbidities are also high.

Labor is considered obstructed when the presenting part of the fetus cannot progress into the birth canal, despite strong uterine contractions. It is more common in humans because the birth canal of a woman is not as straight and wide as in primates, the most frequent cause of obstructed labor is cephalo-pelvic disproportion - a mismatch between the fetal head and the mother's pelvic brim like large fetus of a diabetic woman may be large in relation to the maternal pelvic brim of the pelvis may be contracted, which is more common when malnutrition is prevalent and some other causes may be malpresentation or malposition of the fetus (shoulder, brow or occiput-posterior positions). In rare cases, locked twins or pelvic tumors can cause obstruction [4]. Neglected obstructed labor (OL) is the major cause of both maternal and newborn morbidity and mortality that can only be alleviated by means of operative delivery, either cesarean section or other instrumental delivery (forceps, vacuum extraction or symphysiotomy).
Maternal complications include intrauterine infection, trauma to the bladder and/or rectum and ruptured uterus with consequent hemorrhage, shock or even death. Trauma to the bladder leads to stress incontinence, by far the most severe and distressing obstetric fistula of different types. In the infant, neglected obstructed labor may cause asphyxia leading to stillbirth, brain damage or neonatal death, Obstructed labor ranked 41st in GBD 1990, representing $0.5 \%$ of the burden of all conditions and $22 \%$ of all maternal conditions.

It was estimated to be the most disabling of all maternal conditions. However, until a more comprehensive data collection on all deliveries, especially in the developing world, will become available, self-reports in response to well-designed and well-worded interviews may be the only way to collect information about maternal morbidity [5]. In India, it accounts for $9.5 \%$ of total maternal mortality and this high incidence is a result of unsupervised obstetrics care at periphery combine with poor utilization of health resources, dogmatic traditional approaches during delivery, poor communication, delayed referrals and malnutrition [6].

Most cases of obstructed labor irrespective of underlying cause are usually managed surgically. One of the common problems faced is of a deeply impacted head in the pelvis during the second stage of labor which is technically very difficult to tackle during the cesarean section. The various technique of head delivery in such circumstances has been advocated like pull and push (reverse breech) $[7,8]$ and Patwardhan's.

\section{Obstructed labor disease model and Global} Burden of Disease: When labor is obstructed (compacted pelvis, macrosomia, malpresentation, uterusatony), the fetal head impacts against the soft tissue of the pelvic floor, pinning the bladder base and the urethra against the pelvic bone. It is the duration of impaction without relief rather than the magnitude of the pressure, which determines the degree of tissue necrosis. The fistula site depends greatly on the degree of cervical effacement and dilatation, and the level at which the presenting part impacts. In the absence of any intervention, this condition may last for several days, in which time at the place of the impact the damaged tissue is extending due to lack of vascularization and eventually a hole appears from the vagina into the bladder, and sometimes the rectum. 
At the end of this interval, the fetus dies and is macerated; the mothers are exhausted because of bleeding and or sepsis and they will deliver a stillborn fetus. The consequence of fistula is urinary or fecal incontinence, i.e. permanent leaking of urine or feces through the vagina, a condition that is almost unendurable for women, who have to continue living thereafter unclean, outcast, smelling of urine and feces. In addition to their physical injuries, women who have experienced prolonged obstructed labor often develop serious social problems, including divorce, exclusion from religious activities, separate from their families, worsening poverty, malnutrition, and almost unendurable suffering. Available data on the prevalence of sequelae of obstructed labor is scarce.

For stress incontinence, most studies reveal that ranges from 6 to 29\% [9] Viktrup et al in 1992 found that $1 \%$ of women had daily stress incontinence following delivery [10]. delivery of $21 \%$ and $34 \%$, respectively [11], the risk of postpartum stress incontinence in a developed country [12], however, some other authors report that there is no difference in the prevalence of delivery $[9,13,14]$, baby weighing more than $4000 \mathrm{~g}$ seems to be a predominant factor [15]. For cesarean section, it was assumed that in $90 \%$ of cases of treated obstructed labor a cesarean section is performed, and in the remaining $10 \%$ an instrumental delivery.

For rectovaginal and vesicovaginal fistula, in developing regions the incidence ranges from $0.01 \%$ to $0.08 \%$ of births, no obstetric fistula resulting from obstructed labor is seen today in developed countries. For GBD2000 the obstetric fistula rate was expressed as of $0.08 \%$ of births as a proportion of neglected obstructed labor cases for the AFRO E region. The same rate of $0.08 \%$ of births was used in GBD1990. This results in an incidence rate of obstetric fistula of $2.15 \%$ of neglected obstructed labor cases. This rate was applied to the regional rates of neglected obstructed labor to determine the overall incidence of obstetric fistula.

The general methodology used for mortality estimates of the GBD 2000 is described in Mathers et al. Using this methodology, it was estimated that globally obstructed labor is responsible for $8 \%$ of all maternal deaths [16]. Complications of obstructed labor/sequelae considered for the burden of disease estimates 2000 were cesarean section, stress incontinence and recto-vaginal fistula [17].

\section{Global Health Burden}

Cesarean section: The health state based on 6 dimensions of health: mobility, self-care, usual activities, pain/discomfort, anxiety/depression, cognition. This disability weight will be revised using health stat evaluation data from the WHO World Health Survey in 2003.

Stress urinary incontinence: Women's mental and physical health suffered as a result of their condition. One-quarter of incontinent women believe that their mental health was affected by their incontinence to a moderate or severe extent. Other reported psychological effects included depression, anxiety, irritability, worry, frustration, and tension. Incontinence also affected the desire or ability to take part in recreational or sporting activities. It restricted the type of activity, such as shopping, travel, or going on holiday, that involved unfamiliar places where toilet facilities were unknown or unavailable.

\section{Recto-vaginal and vesicovaginal fistula- Usually} the conditions appear after prolonged and neglected obstructed labor in places where delivery is not appropriately assisted. In developing countries it is usually a feature of a young and malnourished primipara, having obstructed labor and lacking the means for rapid referral to a health facility. These lacunae led us to retrospectively analyze the available techniques (Pull and push) for delivery of deeply impacted head during cesarean sections in terms of feto-maternal morbidity and mortality and to identify the preventable cause of obstructed labor in our setup.

\section{Materials and Methods}

This study was carried out in IPGME and R/ SSKM Medical College from April 2015 to Feb 2019. This is an important referral center in Eastern India, especially for obstetrics patients. In this study frame, 13865patients were referred here for labor and obstructed labor constituted $8.724 \%$ of these referrals. 74 women with impacted head during the second stage of labor undergoing pull technique for delivery during cesarean section included in this study group. Age and parity matched control group consisted of 74 women undergoing conventional method (push technique) during cesarean section were included. Inclusion criteria were patients requiring cesarean section with the following indication; 1) prolong the second stage of labor, 2) failed instrumental delivery 3) deep transverse arrest, 4) arrest in occipito posterior position. 
Exclusion criteria were; 1) uterine rupture, 2) uterine anomaly 3) intrauterine fetal death, 4) medical disorders of pregnancy, 5) antepartum hemorrhage, 6) twin pregnancy.

\section{Procedures adopted in the present study}

Conventional (push technique): After opening the uterus by transverse incision on the lower segment, the patient was the position with knees flexed and leg abducted. An assistant under proper aseptic precaution introduced his hand into the vagina and disimpacted the flexed head back into pelvis. Then the head and subsequently the whole body was delivered abdominally.

Reverse breech (Pull technique): After opening the lower segment of uterus transversely, right hand introduced immediately into the upper segment for a fetal leg. Apply gentle traction on the leg until the other leg appears. With two legs held together, deliver (pull) the body of the fetus out of the uterus. Finally, the baby's wedged head in the pelvis was lifted up gently leading to complete delivery of the baby.

Table-1: Patients characteristics.

\begin{tabular}{|c|c|c|c|}
\hline Parameters. & Reverse breech $n=74$ & Conventional $\mathrm{n}=74$ & $P$ value \\
\hline Obstetrics history Primi para & $44(59.45 \%)$ & $40(54.05 \%)$ & 0.719 \\
\hline Multipara & $25(33.78 \%)$ & $27(36.48 \%)$ & \\
\hline Grand multi & $5(6.75 \%)$ & $7(9.45 \%)$ & \\
\hline Age & Age & & \\
\hline $19 \pm 3$ years & $19 \pm 3$ years & $40(54.05 \%)$ & \\
\hline $23 \pm 3$ years & $23 \pm 3$ years & $32(43.24 \%)$ & \\
\hline $28 \pm 2$ years & $28 \pm 2$ years & $2(2.7 \%)$ & \\
\hline Gestational weeks & & & 0.696 \\
\hline$<37$ week & $13(17.56 \%)$ & $17(22.97 \%)$ & \\
\hline $37-40$ & $57(77.02 \%)$ & $53(72.62 \%)$ & \\
\hline$>40$ week & $4(5.4 \%)$ & $4(5.4 \%)$ & \\
\hline Anemia(gm\%) & & & $\mid<0.001$ \\
\hline$<7$ & $2(2.7 \%)$ & $1(1.35 \%)$ & \\
\hline 7-9 & $32(43.245)$ & $56(75.67 \%)$ & \\
\hline$>9$ & $41(55.41 \%)$ & $16(21.625)$ & \\
\hline BMI & & & 0.003 \\
\hline$<24$ & $34(45.94 \%)$ & $18(24.32 \%)$ & \\
\hline $24-29$ & $28(37.83 \%)$ & $54(72.97 \%)$ & \\
\hline$>30$ & $12(16.21 \%)$ & $2(2.7 \%)$ & \\
\hline Maternal height & & & 0.530 \\
\hline$<144 \mathrm{~cm}$ & $17(22.98 \%)$ & $22(29.73 \%)$ & \\
\hline $144-152 \mathrm{~cm}$ & $33(44.59 \%)$ & $27(36.48 \%)$ & \\
\hline$>152 \mathrm{~cm}$ & $24(32.43 \%)$ & $25(33.78 \%)$ & \\
\hline
\end{tabular}

All cases were administered preoperative IV fluids and antibiotics, preoperative and postoperative hemoglobin levels and the number of blood transfusion required were recorded to assess the blood loss. Standard hospital stays in this study was for five days. Standard anesthesia during cesarean section was spinal and epidural. The maternal outcome including the extension of incision line, uterine artery injury, NICU admission, neonatal convulsion, and death were also observed and compared between the study and control group. Software. The numerical variables were analyzed by Fischer exact test and P-value $<0.05$ was considered as statistically significant.

\section{Results}

There was 24000 singleton birth occurred during the study periods in said institution-IPGMER-SSKMH. One forty eighty women with an impacted head who underwent Pull technique for delivery were matched in terms of age, parity with the same number of controls who had a conventional method for head delivery during cesarean section. The patient's characteristics and demographic data were depicted (Table-1). 
As per the description on the Table-1, no statistical significance was observed of difference in terms of age and parity, gestational period and nutritional status. The varied maternal outcome among two groups (pull vs push) showed in (Table-2) uterine artery injury $(4.05 \%$ vs $24.32 \%<P \quad 0.05)$, bladder injury $(1.35 \%$ VS $4.05 \%-P=0.320$, transverse extension but no uterine artery injury $(9.45 \%$ vs $25.67 \%<\mathrm{P}, 0.05)$ and colporrhexis $(7.69 \%$ vs $17.56 \%-\mathrm{P}<0.05)$.

\section{Table-2: Profile of intra-operative morbidities}

\begin{tabular}{|l|l|l|l|}
\hline \multicolumn{1}{|c|}{$\begin{array}{c}\text { Operation } \\
\text { complication }\end{array}$} & \multicolumn{1}{|c|}{$\begin{array}{c}\text { Reverse breech n } \\
=74\end{array}$} & $\begin{array}{r}\text { Conventional n } \\
=74\end{array}$ & \multicolumn{1}{c|}{$\begin{array}{c}\text { P- } \\
\text { value }\end{array}$} \\
\hline Uterine artery injury & $4(4.05 \%)$ & $19(24.32 \%)$ & 0.0009 \\
\hline Bladder injury & $1(1.35 \%)$ & $3(4.05 \%)$ & 0.31 \\
\hline Transverse extension & $8(9.45 \%)$ & $19(25.94 \%)$ & 0.0002 \\
\hline Vertical Extension & $1(7.97 \%)$ & $14(17.56 \%)$ & 0.009 \\
\hline Hysterectomy & Nil & $2(2.7 \%)$ & 0.24 \\
\hline Blood transfusion & $7(9.45 \%)$ & $16(21.63 \%)$ & 0.0001 \\
\hline
\end{tabular}

Permanent morbidity like hysterectomy was observed in two patients $(2.7 \%)(P=0.24)$ with push technique. Among postoperative morbidity showed in Table-3) febrile complication wound infection and
Increased hospital stay more than seven days were noted in $43.24 \%, 16.21 \%$ and $29.72 \%$ of women undergoing conventional methods respectively.

\section{Table-3: Profile of post-operative morbidities}

\begin{tabular}{|l|l|l|l|}
\hline \multicolumn{1}{|c|}{$\begin{array}{c}\text { Operation } \\
\text { complication }\end{array}$} & \multicolumn{1}{|c|}{$\begin{array}{c}\text { everse breech } \\
\mathbf{n = 7 4}\end{array}$} & $\begin{array}{c}\text { Conventional } \\
\mathbf{n = 7 4}\end{array}$ & \multicolumn{1}{|c|}{$\begin{array}{c}\mathbf{P}- \\
\text { value }\end{array}$} \\
\hline Fever & $10(14.86 \%)$ & $31(43.24 \%)$ & $<0.001$ \\
\hline Wound infection & $2(2.7 \%)$ & $12(16.24 \%)$ & 0.009 \\
\hline Hospital stay & $4(5.45 \%)$ & $22(29.72 \%)$ & $<0.001$ \\
\hline
\end{tabular}

There was a statistically significant difference between the two groups in terms of fetal outcome showed in (Table-4) Neonatal birth weight ranged between $2.56 \mathrm{~kg}$ and $3.67 \mathrm{~kg}$. Apgar score at 5 minutes ranged between 7 and 10in the majority of neonatesThe outcomes in cases (Reverse Group)better in relation to Uterine Artery Injury $(P=0.0009)$, Bladder injury $(P=0.31)$, Transverse Extension (0.0002), Vertical extension (0.009), Hysterectomy (0.24), Blood transfusion (0.0001). The post operatives morbidities in forms of following parameters are favorable in the present study group as mention-Fever $(P<0.001)$, Wound infection $(P=0.009)$, Hospital stay $(P<0.001)$.

Table-4: Fetal outcome

\begin{tabular}{|l|l|l|l|}
\hline \multicolumn{1}{|c|}{ Baby outcome } & \multicolumn{1}{|c|}{ Reverse breech $\mathbf{n = 7 4}$} & \multicolumn{1}{|c|}{ Conventional $\mathbf{n = 7 4}$} \\
\hline Birth weight & & $9(12.16 \%)$ & 0.847 \\
$<2.5 \mathrm{~kg}$ & $11(14.86 \%)$ & $43(58.1 \%)$ & \\
$2.5-3$ & $40(56.05 \%)$ & $22(29.78 \%)$ & \\
$>3 \mathrm{~kg}$ & $23(31.08 \%)$ & & 0.791 \\
\hline Apgar score & & $46(62.18 \%)$ & \\
$7-10$ & $44(59.49 \%)$ & $20(27.02 \%)$ & \\
$4-6$ & $19(25.67 \%)$ & $8(10.81 \%)$ & \\
$0-3$ & $11(14.86 \%)$ & $13(17.56 \%)$ & 0.834 \\
\hline NICU admission & $15(20.27 \%)$ & $2(2.7 \%)$ & 0.1 \\
\hline Convulsion & $3(4.04 \%)$ & $2(2.7 \%)$ & 1 \\
\hline Fracture Ribs & 0 & 0 & 1 \\
\hline Fracture Humorous & $1(1.35 \%)$ & 3 & .41 \\
\hline Skull injury & 0 & & \\
\hline
\end{tabular}

\section{Discussion}

The obstructed labor with the deeply impacted fetal head is an obstetrical emergency situation, which requires a secure delivery technique to prevent undesirable maternal and neonatal consequences [18]. Regarding a difficult fetal delivery, head pushing is the most commonly practiced technique. However, reverse breech extraction has gradually been given higher priority, not only in developing but also in higher resource settings.
Rising rates of intrapartum cesarean sections and the presented significant differences of an uncomplicated compared to a difficult delivery highlight the importance of safe intrapartum care for mother and child $[19,20]$. On one hand, difficult fetal extractions are associated with an increased maternal risk of postpartum hemorrhage with elevated blood loss and [21]. This increased risk results from a prolonged skin incision-delivery time, uterine incision-delivery time, total operation time and are caused by a higher rate of extensions of the uterine wound, T-incisions and additional 
Instrumental support. On the other hand, difficult fetal extraction leads to severe neonatal consequences such as significantly higher rates of neonatal umbilical arterial $\mathrm{pH}<7.15$ and admissions to the neonatal care unit. Therefore, it is important to incorporate alternative methods of fetal delivery into the daily obstetrical routine for a better outcome for mother and child.

With the introduction of the reverse breech method in cesarean sections for obstructed labor in 2014, it was observed that fewer maternal complications with emphasis on a significantly lower rate of extensions of the uterine incision, which has been defined as the primary outcome $(p<0.001)$. Similar results regarding a higher rate of extensions of the uterine incision in cesarean sections performing fetal extraction via push technique were found in earlier publications. Shorter operation time and less blood loss compared to the head pushing method were also evaluated. The present findings correlate with the results of Frass KA et al. [22,23,24], and Veisi et al describing a significant rise of the duration of surgery and of uterine wound extensions, plus higher blood loss in the head pushing group among difficult fetal extractions by comparing the two mentioned delivery techniques.

No statistically significant findings in the present analysis were identified regarding neonatal outcomes when comparing the two extraction methods. Compared to the conventional cephalic delivery, where three skull injuries were found that resulted in severe neonatal complications and even one in neonatal death, none were detected in the reverse breech group. Berhan and Berhan The present baseline criteria of difficult fetal extractions, in general, showed that the risk of having a difficult fetal extraction during cesarean section rises with an increase of cervical dilation, especially when fully dilated. Furthermore, fetuses with larger head circumferences $>35 \mathrm{~cm}$ have a higher risk to not enter the deep pelvis in intrapartum cesarean sections most likely caused by cephalopelvic disproportion and therefore have a lower risk of being impacted in the maternal pelvis.

On the other hand, fetuses with head circumference below $35 \mathrm{~cm}$ or with cephalic malpresentation are more likely to have a difficult extraction caused by impaction in the maternal pelvis. Berhan and Berhan report an increase of overall perinatal mortality in the head pushing group when compared to reverse breech.
Concerning fetal birth trauma Veisi et al, and Bastani et al did not describe any significant fetal differences between the two investigated extraction techniques. In contrast to the present data and former studies, Fasubaa et al. could also prove significant differences in fetal Apgar scores at five minutes and in the rates of neonatal death. However, similar to the results of former studies one extremity fracture caused by reverse breech extraction was described. This fact indicates the need for an even more skillful and gentle approach in the future.

The present baseline criteria of difficult fetal extractions, in general, showed that the risk of having a difficult fetal extraction during cesarean section rises with an increase of cervical dilation, especially when fully dilated. Furthermore, fetuses with larger head circumferences $>35 \mathrm{~cm}$ have a higher risk to not enter the deep pelvis in intrapartum cesarean sections most likely caused by cephalopelvic disproportion and therefore have a lower risk of being impacted in the maternal pelvis. On the other hand, fetuses with head circumference below $35 \mathrm{~cm}$ or with cephalic malpresentation are more likely to have a difficult extraction caused by impaction in the maternal pelvis.

When comparing the different extraction methods (head pushing vs. reverse breech) significant differences in maternal outcome can be seen. In fact, prolonged labor increases the thinning of the lower uterine segment by an engaged fetal head and elevates the risk of damage to the uterine vessels and the lower urinary tract by cephalic delivery via head pushing method. A highly significant reduced rate of extensions of the uterine incision may be explained by the more gentle delivery technique of reverse breach, which also results in shorter operation time for the repair, less blood loss due to fewer lacerations in the broad ligaments and less cervical lacerations, which has also been discussed in former studies. A shorter surgical duration also prevents prolonged anesthesia with potential side effects. Regarding the neonatal outcome, the present data showed less morbidity after reverse breech extraction compared to the head pushing method for obstructed labor. All outcomes show a tendency to a better effect in the reverse breech group. Further research with a higher number of cases is required to determine a significant difference definitely. Despite the lack of statistical significance, the severity of neonatal morbidity shows clinical relevance. 
Originally, the reverse breech technique was also developed to improve the neonatal outcome, with the assumption that mainly tensile forces were acting and therefore the pressure on the child's head could be reduced.

Thus, it was suggested that the reverse breech technique should initially be considered in all intrapartum cesarean sections with a lack of space between the maternal pelvis and the impacted fetal head or when the anterior fetal arm has already dropped out after the uterine incision.

Out of total delivery annually in these institution women with obstructed labor due to impacted head constituted 6. 96\%. This record is probably the tip of the iceberg because of the poor data collection system. In the present study, it was observed that obstructed labor in primigravidae $(84 / 184=56.75 \%)$ mainly. Others associated observation for obstructed labor appeared to be, age $<22$ years $(82 / 148=55.4 \%)$, height $<152 \mathrm{~cm}$ $(99 / 148=66.89 \%), \quad \mathrm{BMI}<24$ and $>30$ $(85 / 148=57.43 \%)$ and moderate anemia $88 / 148=59.45 \%$ ). Abnormal BMI and anemia had a significant association with obstructed labor in the present study $(p \leq 0.05)$. Studies have suggested that young and adolescent girls can face difficulty in delivery as before achieving their maximal growth potential they start childbearing with an inadequate pelvis7. Other literature documents flattening of pelvis usually with height $<152 \mathrm{~cm}$ [25]. So Konje at al concluded nutritional deficiency to be an important causative factor for obstructed labor [26]. Zhang $\mathrm{J}$ et al stated that elevated cholesterol associated with obesity had a deleterious effect on uterine contractility and $\mathrm{Ca}+2$ signaling in human myometrium, leading to ineffective oxytocin-induced contraction [27].

In the present series, it was observed that more intra and postoperative morbidity with the conventional method of head delivery. Uterine artery injury, transverse and vertical extension of uterine incision and blood transfusion requirement were the major morbidity with push technique. Unfortunately, two women undergoing push technique required hysterectomy due to intractable bleeding. Above all, a considerable number of patient in this group developed postoperative febrile complication (32 vs $11 ; \mathrm{p} \leq 0.05$ ) resulting in more days hospital stay(22 vs $4 ; \mathrm{p} \leq 0.05)$ Fassuba at al compared push and pull technique of delivery in impacted head and observed similar complication with push technique.
They suggested that disimpaction of the fetal head and subsequent upward push from below probably resulted in significant higher genital tract injury, subsequent blood loss and increase operating time. They also commented that since the head was being pushed from the vagina to the uterine cavity, the chance of ascending infection was increased leading to more febrile morbidity. They commented that extension of the uterine incision with its resultant hemorrhage, difficult repair and subsequent scar dehiscence might be totally avoided by delivering the fetus by Pull technique.

The current study did not observe any significant difference in fetal outcome by the two delivery methods. Fasuba et al observe significantly more NICU admission, fetal injury, low Apgar score and early neonatal death among women delivered by push method comparison to pull method. Considering the conclusions drawn by various authors Sethuram et al had stressed the required of adequate training for delivery of deeply engage. The current study echoes their views as confidence in this obstetrics skill can help many obstetricians at the periphery to reduce feto-maternal morbidity and mortality resulting in obstructed labor. Simultaneously it will reduce the referral to a tertiary center

In the future, it will be necessary to further establish this pull technique in current daily practice and to intensify the training especially for inexperienced obstetrical staff to ensure safe intrapartum care and prove the statistical relevance of the neonatal outcome. Training tools such as objective structured assessment tools, case-based discussions, video analysis and mini-clinical examinations for complex cesarean sections in obstructed labor are mandatory to improve the trainees' confidence and establish a clinical standard.

Drawbacks Limitation: Provide limitations of the present study.

- The learning curve might be longer for inexperienced surgeons.

- If this procedure is to be routinely performed

- in the future, more surgical training will be required.

- It is a single-center study, with a small sample size required long follow-up required especially reproductive life in future not properly evaluated. 
Needs multicenter Randomized Controlled Trials (RCT).

\section{Conclusion}

This study shows that the reverse breech extraction technique for delivery of deeply impacted head in the second stage cesarean section carries a significantly lower risk of extension of uterine incision compared with the push method. This also associated with a lower risk of infection, lower operative time and less operative blood loss. The reverse breech technique entails less Intra and postoperative morbidity. Decreasing the rate of obstructed labor may be possible by preventing teenage pregnancy, adequate BMI, correction of anemia, ensuring adequate nutrition to girls since infancy and creating social awareness of the magnitude of the problem. In developing countries where the incidence of obstructed is quite high, supervised training and application of reverse breech technique (pull method) may improve fetomaternal outcome.

\section{What does the study add to the existing knowledge?}

The reverse breech method is associated with less maternal morbidity than the head pushing method for the extraction of a deeply impacted fetal head during intrapartum cesarean delivery.

The beneficial maternal-fetal results of performing the reverse breech procedure indicate that it is a reliable alternative to the standard head pushing method and should preferably be used in deeply impacted fetal head situations during cesarean section in advanced labor.

\section{Author's contribution}

Dr. Dipnarayan Sarkar: Defining, planning, implementation-monitoring, and fine-tuningevaluating, capitalizing.

Dr. Sarbeswar Mandal: Detail description of situation and analysis to find out with prioritizing the problems to identify the root, the real problem which is addressed for turning ideas into research questionnaires.

Dr. Masihon Murmu: Manuscripts review and approval- making a meeting with all members (all authors) discussed, criticized, modified, rectified and finally edited with approval.
Dr. Sarumathy K.A.: Conduct study (forms, data captures, ensure compliances), data processing (data collection).

Dr. Rituparna Raj: Statistical analysis, interpretation, explanation.

Dr. Shabina Khatoon: Archiving of data, reporting, and dissemination (report writing, presentation, publication).

\section{Acknowledgments}

Authors would like to thank all the patients recruited in the study and all the members of the Department of Obstetrics and Gynecology and thankful to the Institutional Ethics Committee, IPGMER-SSKMH, Kolkata, West Bengal, India.

\section{Reference}

01. Ould El Joud D, Bouvier-Colle M-H, MOMA Group. Dystocia- study of its frequency and risk factors in seven cities in west Africa. Int J Gynaecol Obstet. 2001;74(2)171-178.

doi: [10.1016/s0020-7292(01)00407-6] [Crossref]

02. Dolea C, Abu Z. Global burden of obstructed labor in the year 2000, Global burden of Disease 2000 Evidence andInformation for policy (EIP). WHO. Geneva,2003. Available at:

[Crossref] [Crossref]

03. Fortney JA, Smith JB. Measuring maternal morbidity, in Safe Motherhood Initiatives-critical issues. Eds Berer $M$ and Ravindran TKS, Reproductive Health Matters, Blackwell Science. 1999.

[Crossref]

04. Maternal Mortality Update-UNFPA. Maternal Mortality Update-UNFPA Assistance of Maternal Mortality Prevention Activities- An Overview. UNFPA. 1998-1999.

Available at [Article] [Crossref]

05. Murray, Christopher J L, Lopez, Alan D and World Health Organization. Health dimensions of sex and reproduction - the global burden of sexually transmitted diseases, HIV, maternal conditions, perinatal disorders, and congenital anomalies / edited by Christopher J L, Murray, Alan D Lopez. Boston- Harvard School of Public Health. (1998).

[Article] [Crossref] 
06. Fasubaa OB, Ezechi OC, Orji EO, Ogunniye SO, Akindele ST, Loto OM, et al. Delivery of the impacted head of the fetus at cesarean section after prolong obstructed labor- a randomized comparative study of two methods. J Obstet Gynaecol. 2002;22(4)375-378.

doi: [10.1080/01443610220141290] [Crossref]

07. Levy R, Chernomoretez T, Appleman Z, Levin D, Or $Y$, Hagay $Z$ J. Head pushing versus reverse breech extraction in cases of impacted fetal head during cesarean section. Eur J Obstet Gynec Reprod Biol. 2005; 121(1)24-26.

doi: $\quad 10.1016 /$ j.ejogrb.2004.09.014 [Crossref]

08. Mukhopadhay P, Naskar T, Dalui R, Hazra S, Bhattacharya D. Evaluation of patwardhan's technique -a four year study in a rural teaching hospital. J Obstet Gynecol India. 2005;55;244246.

[Crossref]

09. Mason L, Glenn S, Walton I, Appleton C. The prevalence of stress incontinence during pregnancy and following delivery. Midwifery. 1999,15(2)120-128.

doi: [10.1016/s0266-6138(99)90008-6] [Crossref]

10. Viktrup L, Lose MD, Rolff M, Barfoed K. The symptoms of stress incontinence caused by pregnancy or delivery in primiparas. Obstet Gynecol J. 1992;79(6)945-949.

[Crossref]

11. Meyer S, Schreyer A, De Grandi P, Hohlfeld P. The effects of birth on urinary continencemechanisms and other pelvic floor characteristics. Obstet Gynaecol. 1998;92(4)613-618.

doi: [10.1016/s0029-7844(98)00248-8] [Crossref:Crossref]

12. Van Kessel K, Reed S, Newton K, Meier A, Lentz $G$. The second stage of labor and stress urinary incontinence. Am J Obstet Gynecol. 2001;184(7)1571-1575.

doi: [10.1067/mob.2001.114856] [Crossref]

13. Wilson PD, Herbison RM, Herbison GP. Obstetric practice and the prevalence of urinary incontinence three months after delivery. $\mathrm{Br} \mathrm{J}$ Obstet Gynaecol. 1996;103(2)154-161.

doi: $\quad[10.1111 / j .1471-0528.1996 . t b 09668 . x]$ [Crossref]
14. MacArthur C, Lewis M, Bick D. Stress incontinence after childbirth. $\mathrm{Br} J$ Midwifery. 1993;1(5)207-213.

[Crossref:Crossref]

15. Groutz A, Gordon D, Keidar R, Lessing JB, Wolman I, David MP, et al. Stress urinary incontinence- prevalence among nulliparous compared with primiparous and grand multiparous premenopausal women. Neurourol Urodynam. 1999;18(5)419-425.

doi:

$[10.1002 /($ sici) $1520-$

6777(1999)18:5\%3C419: :aid-nau2\%3E3.0.co;2-z]

[Crossref]

16. Mathers $C D$, Stein $C$, Tomijima N, Ma Fat $D$, Rao $C$, Inoue $M$, Lopez $A D$, Murray CJL. Global Burden of Disease 2000- Version 2 methods and results. Geneva. World Health Organization.

(2002). Available at [Article:Article] [Crossref]

17. Dolea C, AbuZahr C. Global burden of obstructed labor in the year 2000, Global burden of Disease 2000 evidence and Information for policy (EIP). WHO. Geneva, 2003.

Available at [Article] [Article]

18. Jeve YB, Navti OB, Konje JC. Comparison of techniques used to deliver a deeply impacted fetal head at full dilation- a systematic review and meta-analysis. BJOG. 2016;123;(3)337345.

doi: [10.1111/1471-0528.13593] [Crossref]

19. Unterscheider J, McMenamin M, Cullinane F. Rising rates of caesarean deliveries at full cervical dilatation- concerning trend. Eur J Obstet Gynaecol Reprod Biol. 2011;157(2)1414. doi: [10.1016/j.ejogrb.2011.03.008] [Crossref]

20. Veisi F, Zangeneh M, Malekkhosravi S, Rezavand N. Comparison of "push" and "pull" methods for impacted fetal head extraction during cesarean delivery. Int J Gynaecol Obstet. 2012;118(1)46. doi: [10.1016/j.ijgo.2011.12.027] [Crossref]

21. Saha PK, Gulati R, Goel P, Tandon R, Huria A. Second stage caesarean section- evaluation of patwardhan technique. J Clin Diagn Res. 2014;8(1)93-95.

doi: $[10.7860 / \mathrm{jcdr} / 2014 / 6709.3782] \quad$ [Crossref] 
22. Konje JC, Lapipo O. Nutrition and obstructed labor. Am J Clin Nutr. 2000;72(1);291S-297S. doi: [10.1093/ajcn/72.1.291s] [Crossref]

23. Berhan Y, Berhan A. A meta-analysis of reverse breech extraction to deliver a deeply impacted head during cesarean delivery. Int J Gynaecol Obstet. 2014;124(2)99-105.

doi: [10.1016/j.ijgo.2013.08.014][Crossref:Crossref]

24. Frass KA, Al Eryani A, Al-Harazi AH. Reverse breech extraction versus head pushing in caesarean section for obstructed labour. Saudi Med J. 2011;32(12)1261-1266.

[Crossref]
25. Bastani P, Pourabolghasem S, Abbasalizadeh F, Motvalli L. Comparison of neonatal and maternal outcomes associated with head-pushing and head-pulling methods for impacted fetal head extraction during cesarean delivery. Int J Gynaecol Obstet. 2012;118(1)1-3.

doi: [10.1016/j.ijgo.2012.03.005] [Crossref]

26. Lawson JB, Stewart DD. eds Obstetrics and Gynecology in the tropics and developing countries. London Edward Arnold PRESS. 1967; 172-202.

[Crossref]

27. Zhang J,Kendric A, Quenby s, wray s. Contractility and Calcium Signaling of Human Myometrium are profoundly Affected by Cholesterol Manipulation; Impaction in Labor?. Reprod Sci. 2007;14(5)456-466.

doi: [10.1177/1933719107306229] [Crossref] 